\title{
Guerra Fria, terra seca: o "perigoso" Nordeste brasileiro sob o olhar da CIA e da imprensa estadunidense no alvorecer dos anos 1960
}

\section{Pedro Carvalho Oliveira ${ }^{\mathrm{I}}$}

Resumo: o presente trabalho objetiva examinar a visão sobre o Nordeste brasileiro construída pela Central Intelligence Agency (CIA) e a imprensa estadunidense entre os anos 1959 e 1964, sob o receio quanto a então recente Revolução Cubana e como este fato fez emergir preocupações entre as potências do bloco capitalista em relação à América Latina, motivadoras para elaborações políticas em torno da região brasileira. Numa relação de congruência, o Estado americano e os meios de comunicação desenvolveram comparações entre o Nordeste do Brasil e Cuba que encontraram eco no Brasil. Nossa hipótese é de que essa construção sobre o Nordeste sinaliza para a edificação de processos de hegemonia e criação de consenso, de acordo com o que foi pensado por Antonio Gramsci, cujos resultados se encontram, em certa medida, na visão sobre o Nordeste e sobre os nordestinos existentes no Brasil hoje.

Palavras-chave: Guerra Fria; Nordeste; América Latina.

\section{Cold War, dry land: the "dangerous" Brazilian Northeast between the CIA and the American press in the rise of the 1960's}

\begin{abstract}
The present paper aims to examine the view on the Brazilian Northeast constructed by the Central Intelligence Agency (CIA) and the American press between 1959 and 1964, under the recent Cuban Revolution and how this fact raised concerns among the powers of the capitalist block about Latin America, motivating political elaborations around the Brazilian region. In a congruent relationship, the American State and the media developed comparisons between the Brazilian Northeast and Cuba that found echo in Brazil. Our hypothesis is that this construction on the Northeast is part of the construction of hegemonic power and consensus, according to what was thought by Antonio Gramsci, whose results are to a certain extent in the view on the Northeast in Brazil today.
\end{abstract}

Keywords: Cold War; Northeast; Latin America.

Artigo recebido em 15/12/2017 e aprovado em 20/02/2018.

Cadernos do Tempo Presente, São Cristóvão-SE, v. 09, n. 01, p. 64-81, jan./jun. 2018| http://www.seer.ufs.br/index.php/tempo 


\title{
GUERRA FRIA, TERRA SECA: O "PERIGOSO" NORDESTE BRASILEIRO SOB O OLHAR DA CIA E DA IMPRENSA ESTADUNIDENSE NO ALVORECER DOS ANOS 1960
}

\author{
PEDRO CARVALHO OLIVEIRA
}

\section{Introdução}

O presente artigo tem como objetivo empreender uma breve e introdutória análise de possibilidades de estudos a respeito do interesse dos Estados Unidos no Nordeste brasileiro entre os anos de 1959 e 1964, visto como região propensa a levantes "subversivos" em decorrência de sua pauperização estrutural e histórica. Após a Revolução Cubana de 1959 e do alinhamento das forças revolucionárias ao bloco soviético, os EUA passaram a temer a perda de sua hegemonia com novas revoluções congêneres no hemisfério. Assim, fazendo comparações entre o Nordeste brasileiro e Cuba, bem como outros países latino-americanos onde movimentos de caráter revolucionário se iniciavam no campo, documentos da Central Intelligence Agency (CIA), importantes veículos de comunicação como o jornal The New York Times e canais de TV estadunidenses como a $A B C$, entre outros meios de comunicação, inclusive brasileiros, reportaram o Nordeste como região de disputa entre socialistas, em meio à qual os EUA deveriam intervir.

Nesse processo, discursos hegemônicos foram criados e transmitidos sendo, nesse sentido, necessário pensarmos como esse processo foi fundamental para a) desenvolver um consenso sobre o suposto perigo que representava a região e, assim, legitimar intervenções; b) desenvolver intervenções que partissem de imagens particulares já existentes no Brasil sobre o Nordeste e c) verificarmos como estes discursos hegemônicos encontraram respaldo no Brasil. Além disso, diante de uma conjuntura presente na qual o Brasil vive uma intensa crise política amplificada desde aproximadamente 2013, é possível encontrarmos ecos destes discursos, da criação desta imagem, em meio aos antagonismos políticos entre esquerda e direita vigorosamente presentes nos campos onde estes embates ocorrem, como nas redes sociais virtuais, representando assim uma permanência a ser averiguada.

Acreditamos que tais discursos operam no sentido de defender uma hegemonia e, para tanto, se fazem de interesses políticos comuns às classes que se beneficiam desse processo. Para defendermos esta hipótese e compreendermos o referido processo de defesa destes interesses, utilizaremos os debates de Antonio Gramsci ${ }^{\text {II }}$ sobre consenso e hegemonia, bem como sobre os aparelhos privados de hegemonia, visto que a linguagem dos mecanismos de vigilância estatais estadunidenses são correlatos aos interesses das classes superiores brasileiras, encarregadas de retratar à sua forma, reforçando as diretrizes culturais das quais são beneficiárias, os motivos pelos quais o Nordeste poderia sofrer uma revolução socialista nos anos 1960.

Buscando um norte para a análise proposta, destacamos a necessidade de pensarmos o papel da história nas relações internacionais para além do papel da economia, das implicações jurídicas ou burocráticas, nos servindo de sua validade em exames centrados nas disputas políticas por poder e sua influência na e pela cultura. Cabe a nós o entendimento sobre "o peso das heranças históricas no tempo presente, a força da cultura nas relações internacionais, entre tantos outros temas" "III, ou seja, sobre como estes componentes que detectamos são imprescindíveis ao tratarmos de um momento de intensas e oscilantes negociações entre dois países como foi o período histórico por nós delimitado.

Cadernos do Tempo Presente, São Cristóvão-SE, v. 09, n. 01, p. 64-81, jan./jun. 2018| http://www.seer.ufs.br/index.php/tempo 


\section{GUERRA FRIA, TERRA SECA: O "PERIGOSO" NORDESTE BRASILEIRO SOB O OLHAR DA CIA E DA IMPRENSA ESTADUNIDENSE NO ALVORECER DOS ANOS 1960}

\section{PEDRO CARVALHO OLIVEIRA}

Tendo isso em vista, vale ressaltarmos que um dos maiores problemas envolvendo as pesquisas sobre a relação dos Estados Unidos com outros países, especialmente quando esses exames se direcionam à influência do país como potência política, está em captar apenas a predominância impositiva dos interesses estadunidenses, como se as outras nações não possuíssem interesses e forças políticas próprias, estando indefesas aos mandos imperialistas. Via de regra, tais análises ignoram importantes tensionamentos destas relações e não costumam desvelar a existência, em outros países, de classes hegemônicas interessadas ou não nas intervenções estadunidenses, algo decisivo para a efetivação de sua influência. Nossa pesquisa busca também reduzir esse tipo de perspectiva.

\section{O Nordeste na encruzilaha dos recentes embates políticos brasileiros}

Quando em 26 de outubro de 2014 a então presidente Dilma Rousseff, do Partido dos Trabalhadores (PT), foi reeleita no segundo turno após um pleito apertado contra o candidato de oposição Aécio Neves, do Partido da Social-Democracia Brasileira (PSDB), milhares de eleitores se manifestaram de forma indignada nas redes sociais virtuais, onde enfrentamentos verbais já ocorriam desde antes das eleições e sinalizavam para a intensa polarização da sociedade frente aos projetos de "esquerda" e de "direita", entre situação e oposição. Naquele momento, os escândalos revelados pela famigerada "Operação Lava Jato", fossem eles verossímeis ou não, já haviam desgastado em muito a imagem do PT e o pouco interesse de Dilma em jogar o jogo do campo político parecia fazer o mesmo com a petista. Além disso, Dilma havia preterido seu programa político em nome da reeleição, o que incomodou profundamente seus eleitores. Assim, a indignaçao dos eleitores contrários a ela alcançou níveis gritantes.

Uma conta na rede social virtual Twitter chamada "Culpa do Nordeste"IV reuniu, com o objetivo de denunciá-las, mensagens de usuários culpabilizando os nordestinos pela manutenção do PT no poder e, com isso, pela permanência de um governo que sintetizava, para muitos eleitores, a corrupção. Os usuários xingavam os nordestinos e os tratavam como desprovidos de inteligência, incapazes de tomar decisões eleitorais importantes, naturalmente inferiores e interessados apenas no assistencialismo petista. A grande maioria dos tweets afirmava que os nordestinos, ao terem supostamente garantido a vitória de Dilma nas urnas, estavam interessados na perpetuação de "esmolas" fornecidas por meio de benefícios sociais como os projetos "Bolsa Família" e "Minha Casa, Minha Vida", intensamente difundidos em uma região do Brasil historicamente marcada pela pobreza estrutural.

A publicação do usuário @brunin98_, feita após o encerramento da votação no segundo turno das eleições de 2014, diz: "NORDESTE FODEU O BRASIL CAMBADA DE CABEÇA CHATA FILHOS DE PUTA". Outro usuário, @1ucaschaves7, publicou: "Nordeste provando que merece passar fome e sede, bando de cabeça chata". @alex_rochaaa, outro usuário da rede social, escreveu: "Esses cabeça chata do nordeste onde a maioria vive de bolsa família vai mudar governo pra que? Ganham pra ficar deitados na rede". Os exemplos continuam e se estendem para além da data na qual Dilma foi reeleita. Também acompanham a progressão da candidata nas

Cadernos do Tempo Presente, São Cristóvão-SE, v. 09, n. 01, p. 64-81, jan./jun. 2018| http://www.seer.ufs.br/index.php/tempo 


\section{GUERRA FRIA, TERRA SECA: O "PERIGOSO" NORDESTE BRASILEIRO SOB O OLHAR DA CIA E DA IMPRENSA ESTADUNIDENSE NO ALVORECER DOS ANOS 1960}

\section{PEDRO CARVALHO OLIVEIRA}

intenções de voto antes das eleições, atribuindo aos nordestinos o seu crescimento sobre outros adversários considerados mais competentes pelos que xingavam seus opositores.

Quando Dilma foi eleita pela primeira vez em 2010, suscedendo Luís Inácio Lula da Silva e dando início ao nono ano de governo do PT, um caso de discurso de ódio contra os nordestinos se tornou emblemático. Dois anos depois de ter postado um tweet no qual dizia: "Nordestino não é gente, faça um favor a $\mathrm{Sp}$, mate um nordestino afogado", uma estudante de direito paulistana, contrária a Dilma e ao PT, foi condenada a prestar mais de um ano de serviço comunitário ${ }^{\mathrm{V}}$. A mensagem dela, uma reação à vitória da candidata que não era a sua, se manifestava para além de suas convicções partidárias; aludia também à seca do sertão nordestino e, como consequência disso, a uma suposta migração massiva de sua população para o Sudeste do país, sobretudo a São Paulo.

A aversão aos nordestinos partindo de populações concentradas em regiões mais ao sul do mapa não é uma novidade. As ideias sobre as quais estas ocorrências acima citadas se edificaram surgiram como parte de um longo processo. Desde o início do século XX, em meio a disputas por poder institucional e atenção quanto ao desenvolvimento industrial do Sudeste, ideólogos e teóricos como Oliveira Vianna e Dionísio Cerqueira ajudaram a construir historicamente o Nordeste e os nordestinos como exemplos de degeneração racial, do ponto de vista físico e intelectual. Buscaram provar cientificamente suas características ditas inferiores como uma consequência do encontro entre um habitat desfavorável e a mestiçagem, completamente distintos dos processos eugenistas pelos quais teria passado a população do Centro-Sul. Neste sentido, a superioridade das populações coloniais europeias, como as do Sul e as de São Paulo, não seria historicamente elaborada, pois, para eles, "o Nordeste era inferior por sua própria natureza" $\mathrm{VI}$. Assim, deveria ser descartado dos projetos desenvolvimentistas e ter menos assistência do orçamento público.

Claro que este discurso não incidia sobre toda a região, mas principalmente sobre os mais pobres, incapazes de obter sucesso diante do chamado "darwinismo social" tão difundido à época e defendido por estes ideólogos. Esse discurso era um mecanismo para atrair a atenção do poder central no sentido de desenvolver as regiões mais economicamente ativas do país e em crescente progresso modernizador, num contexto onde estudos sobre higienização e "pureza racial" estavam em voga, junto à acelerada industrialização do Brasil sobretudo a partir dos anos 1930. Com isso, o nordestino passou a ser estigmatizado e historicamente construído como um sujeito inferior, durante muitos anos, em meio a embates econômicos que tornavam a região Nordeste, permeada por um sistema colonial ultrapassado, dispensável frente aos avanços econômicos do Sudeste no curso da projeção industrial.

Estas perspectivas sobre o Nordeste ignoravam a responsabilidade da ação humana na região explorada até então, berço da colonização portuguesa e terreno para um sistema industrial de características semi-feudais, consequência do prolongado fechamento da Península Ibérica frente à presença muçulmana. A implantação do sistema monocultor açucareiro colonial e da exploração exaustiva dos recursos naturais e humanos para o seu sucesso, obtido pela remessa de produtos para o exterior, não foi um fenômeno da natureza. O Nordeste possuía tantas mazelas na primeira metade do século XX por razões humanas, não apenas por razões naturais. Foi por essas razões que

Cadernos do Tempo Presente, São Cristóvão-SE, v. 09, n. 01, p. 64-81, jan./jun. 2018| http://www.seer.ufs.br/index.php/tempo 


\section{GUERRA FRIA, TERRA SECA: O "PERIGOSO" NORDESTE BRASILEIRO SOB O OLHAR DA CIA E DA IMPRENSA ESTADUNIDENSE NO ALVORECER DOS ANOS 1960}

\section{PEDRO CARVALHO OLIVEIRA}

os sertanejos do chamado Nordeste Ocidental (distantes do litoral) sofriam com as secas e com a fome, com as pouquíssimas possibilidades de subsistência e com a necessidade vital de migrar para regiões como São Paulo e Rio de Janeiro ${ }^{\mathrm{VII}}$. O projeto exploratório açucareiro extrapolou os limites naturais da fauna e da flora nordestina, inviabilizando outro tipo de plantio. O sistema de produção para o exterior também desfavoreceu os trabalhadores e minou suas possibilidades de crescimento econômico.

Para Durval Muniz de Albuquerque Jr. ${ }^{\text {VIII }}$, as elites intelectuais nordestinas forjaram durante estes embates a cultura do Nordeste conhecida hoje, como um esforço para denunciar o desleixo do poder central em relação às necessidades da região então preterida. Da forma como é colocado por ele, parece que esse processo teve como guia o interesse pela retomada do prestígio das elites nordestinas frente ao ânimo industrial corrente no então Centro-Sul. Para Josué de Castro ${ }^{\mathrm{IX}}$, no entanto, essa produção é também resultado e ao mesmo tempo impulsionadora de uma tomada de consciência do povo nordestino sobre sua situação. Estes haviam descoberto um outro Brasil, o do Sul, no qual a mortalidade não aparentava ser tão fatalista e onde a vida corria com menos penúria, o que consequentemente motivou este povo a não mais desejar se sujeitar ao sistema de produção encontrado no Nordeste. Nesse sentido, o autor compreende o desenvolvimento cultural nordestino não apenas como aquele dirigido pelas elites intelectuais.

Iná Elias de Castro $^{\mathrm{X}}$ faz considerações importantes a esse respeito. Segundo ela, respaldada por uma consistente bibliografia, a imagem da pobreza e das necessidades infindáveis existentes no Nordeste são motivadas pela própria dinâmica da política brasileira, na qual os poderes regionais costituídos historicamente buscam manter seus privilégios de classe frente a uma reestruturação do modo de produção nacional. Ou seja, reproduzem a ideia de pobreza eterna que sombreia a região para conseguirem recursos financeiros e poder de influência que deem sustentáculo à continuidade das estruturas sociais reinantes no Nordeste. Assim, as elites nordestinas reagiriam de forma conservadora ao desenvolvimento capitalista e barganharia a sua legitimidade.

Porém, o que o Estado ganharia nessa relação? O poder central, também buscando legitimidade, defere às elites regionais o poder de barganha e certa autonomia em seus territórios, mesmo que esta dinâmica se altere em alguns momentos e se desequilibre, ora pendendo para as elites locais, ora pendendo para o poder central. No final das contas, o Nordeste seria, em decorrência disso, uma região que se constituiu historicamente como portadora de resíduos de antigas estruturas sócio-econômicas e políticas, das quais não consegue se desfazer. Em linhas gerais, as elites locais usariam o discurso da pobreza como recurso para a manutenção do seu status quo ${ }^{\mathrm{XI}}$.

Embora possamos concordar com partes de todas estas perspectivas, nos aproximamos mais da defendida por Josué de Castro ${ }^{\text {XII }}$ pois ele empreende um exame da construção cultural do Nordeste como uma reação à hegemonia central, principalmente, em meio a um embate por posições de poder, algo que os outros autores esquecem de fazer, ou preferem não fazer. Diferentemente dele, Albuquerque Jr. ${ }^{\text {XIII }}$ e Iná Elias de Castro ${ }^{X I V}$, por exemplo, compreendem esse processo como mera manobra das elites agrárias da região, como mecanismo para restaurar o prestígio e a dominação

Cadernos do Tempo Presente, São Cristóvão-SE, v. 09, n. 01, p. 64-81, jan./jun. 2018| http://www.seer.ufs.br/index.php/tempo 


\section{GUERRA FRIA, TERRA SECA: O "PERIGOSO" NORDESTE BRASILEIRO SOB O OLHAR DA CIA E DA IMPRENSA ESTADUNIDENSE NO ALVORECER DOS ANOS 1960}

\section{PEDRO CARVALHO OLIVEIRA}

destas classes. De fato, pensamos que isso existiu e é fundamental para compreender tais processos, mas não devemos, como os autores, reduzir esse movimento à incapacidade das elites aceitarem uma derrota, quando a cultura promovida por intelectuais nordestinos da época já existia, já era também produzida por pobres e populações sertanejas, e em muito se relacionava com as estruturas dos meios de produção existentes ali historicamente. Não podemos reduzir a cultura de uma região a um período particular. É preciso considerarmos que embora a hegemonia dirigente fosse forjada pelas classes dominantes, herdeiras da monocultura açucareira, do escravismo, e desejosas quanto à permanência desse sistema, os camponeses pobres e assalariados também reconheciam a falta de avanços em sua realidade, que inclusive motivaria migrações massivas ao chamado Centro-Sul. Também não podemos ignorar que, como mostrado pelo autor, o Centro-Sul se beneficiou sobremaneira da agricultura nordestina para desenvolver sua industrialização, agindo como centro metropolitano recebendo de sua periferia as matérias-primas necessárias ao seu desenvolvimento e do seu povo.

Foi no período em que o Nordeste vinha se consolidando como região territorial específica, enquanto a difusão de uma cultura nordestina reafirmava sua importância histórica, que a Aliança Para o Progresso (APP) surgiu. O projeto, surgido durante o mandato do então presidente dos Estados Unidos John F. Kennedy, tinha como objetivo acelerar o desenvolvimento econômico e social entre os países da América Latina a fím de diminuir a pobreza. Por trás da pretensa boa intenção do projeto, para o qual os EUA desenbolsariam milhões de dólares, estava a necessidade de inserir o Brasil na dinâmica comercial capitalista e o receio quanto à chegada do socialismo ao hemisfério após a Revolução Cubana em 1959 e seu precoce alinhamento com o bloco soviético.

Em relação ao Brasil, a preocupação dos EUA era fundamentada na importância do país para a América Latina, sendo o maior e um dos seus mais economicamente relevantes parceiros, bem como pela situação vivida na região Nordeste. Essa preocupação também se relacionava com a fragmentação política e territorial do país, herança histórica de sua colonização. Tad Szulc, correspondente do The New York Times, escreveu em 1960 uma reportagem na qual expunha ao povo estadunidense o perigo de o Nordeste se tornar uma nova Cuba, as características de isolamento da região permitida por suas elites e a necessidade de reduzí-las. Seu artigo revelava "de logo, que as perspectivas de uma situação revolucionária estavam aumentando naquela área do Nordeste brasileiro, sob a pressão do pauperismo generalizado e agravado pela calamidade das secas periódicas". Em seguida, acusava: "a miséria é explorada pela crescente influência esquerdista nas cidades superpovoadas"XV. Por isso, era necessário que as forças democráticas capitalistas agissem o quanto antes. Szulc estava em perfeita sintonia com as análises da Central Inteligence Agency (CIA) sobre a situação, mas, talvez, não por mera coincidência.

Em um documento datado de agosto de 1961, intitulado Soviet bloc intrests in Brazil's Northeast ("interesses do bloco soviético no Nordeste brasileiro") "XVI, a CIA informa que o bloco soviético estaria, por meio de seus aliados, oferecendo subsídios aos estados do Nordeste brasileiro, região na qual teria interesse em disseminar sua ideologia. O memorando especula e faz afirmações sem apresentar provas. Comenta que os soviéticos, bem como a Alemanha Oriental, pretendem fornecer ajuda em diversos

Cadernos do Tempo Presente, São Cristóvão-SE, v. 09, n. 01, p. 64-81, jan./jun. 2018| http://www.seer.ufs.br/index.php/tempo 


\title{
GUERRA FRIA, TERRA SECA: O "PERIGOSO" NORDESTE BRASILEIRO SOB O OLHAR DA CIA E DA IMPRENSA ESTADUNIDENSE NO ALVORECER DOS ANOS 1960
}

\section{PEDRO CARVALHO OLIVEIRA}

setores, inclusive no desenvolvimento fabril nordestino. Outras contribuições viriam de países como a República Tcheca, a Polônia e a Hungria, por meio da perfuração de poços, irrigação e verba para energia e estrutura, tudo isso durante o governo de Jânio Quadros.

O então presidente do Brasil teria emitido uma nota à URSS dizendo o seguinte:

\begin{abstract}
Temos recebido valiosa ajuda de outras fontes, mas não na proporção das nossas necessidades, na proporção necessária para melhorar nossa capacidade de trabalho (...) Para o Brasil, é importante reforçarmos trocas com a União Soviética. Temos algumas coisas a oferecer e muito a receber. A ciência, a tecnologia, os recursos acumulados pela corrida da URSS em direção ao progresso pode estimular o crescimento do meu país no momento em que o Brasil decidiu quebrar a rotina da miséria, da doença e da ignorância. XVII
\end{abstract}

Esses fatos ocorreram diante do estabelecimento da Política Externa Independente (PEI) brasileira, por meio da qual o país buscava uma flexibilização de suas relações externas sem torná-las unilaterais sobretudo diante da caça por influência entre EUA e URSS, ainda que Jânio Quadros mantivesse um visível repúdio ao comunismo. Este programa de política exterior, embora almejasse continuidades a longo prazo, serviu de mecanismo para o atendimento de objetivos mais imediatos, seguindo o que San Tiago Dantas ${ }^{\mathrm{XVIII}}$ (2011) sugere como necessário a programas deste tipo.

A impressa de Recife, ainda segundo o relatório, noticiou que Mikhail P. Georgadze, chefe de uma missão soviética, teria oferecido milhões em recursos para o desenvolvimento do Nordeste brasileiro, além de técnicos para analisarem as regiões castigadas pela seca. Ao que parece, o interesse da URSS se mostrava muito mais institucional do que civil, incidindo a priori sobre as estruturas do que sobre a ideologia, ao menos de acordo com o que surge nos relatórios. Pouco é detalhado sobre as ações externas dos comunistas nas Ligas Camponesas, por exemplo, se limitando ao possível contato de Francisco Julião, um de seus organizadores, com Cuba. Sobre isso escreveremos mais adiante.

\section{Em terra árida germina subversão? Análises dos EUA sobre o perigo nordestino}

O memorando supracitado afirma que, segundo reportagens de rádios e jornais, desde 1959 diferentes agentes de países ligados ao bloco soviético ofereceram ajuda para desenvolver o Nordeste, aplicando verbas e serviços técnicos, todos eles estudados ou solicitados pelo Brasil. Ou seja, antes mesmo de Szulc escrever o seu artigo. Embora possamos dizer que sua análise tenha chamado a atenção para o caso nordestino, seria leviano acreditarmos que os EUA desconheciam os interesses soviéticos em desenvolver a região antes disso. Afinal, desde fins dos anos 1950 a potência hemisférica já necessitava "fazer frente a uma ativa política externa soviética no Terceiro Mundo e ao fortalecimento global e estratégico de seu rival"XIX .

Em 1958, as atenções dos EUA para a América Latina foram fortemente cuidadosas. Primeiro, em decorrência do início das lutas revolucionárias em Cuba e, em segundo, pelo lançamento do Plano Pan-Americano, que chamava a atenção de outros

Cadernos do Tempo Presente, São Cristóvão-SE, v. 09, n. 01, p. 64-81, jan./jun. 2018| http://www.seer.ufs.br/index.php/tempo 


\section{GUERRA FRIA, TERRA SECA: O "PERIGOSO" NORDESTE BRASILEIRO SOB O OLHAR DA CIA E DA IMPRENSA ESTADUNIDENSE NO ALVORECER DOS ANOS 1960}

\section{PEDRO CARVALHO OLIVEIRA}

países da região para a necessidade cada vez maior de um plano de auxílio solidário. Foi nesse momento também que Juscelino Kubitschek, suscessor de Quadros após a sua renúncia, reduziu as relações bilaterais com os EUA e passou a ampliar as relações multilaterais com outros países, inclusive com o bloco soviético ${ }^{\mathrm{Xx}}$. Uma consequência das precárias concessões prometidas pelos EUA com a Operação Pan-Americana (OPA), esgotada em 1959, cumprindo pouco atendimento às demandas brasileiras e fazendo JK retomar a via varguista para ensaiar uma real multilaterização ${ }^{\text {XI }}$.

Num importante documento liberado recentemente pela CIA, intitulado The economic-military strenghtening of Brazil, a factor of main importance for the security of the U.S.A. and of the democratic world ("o fortalecimento econômico-militar do Brasil, um fator de prioritária importância para a segurança dos EUA e do mundo democrático"), produzido no final dos anos 1950, fica clara a importância dada pelos estadunidenses ao Nordeste como território militar estratégico e região de possível efeverscência socialista. No campo ideológico, o documento sugere a neutralização e eliminação de focos socialistas entre os camponses, a exemplo das Ligas Camponesas, engajadas na diminuição de disparidades sociais e no atendimento de necessidades básicas, colocando em cheque o sistema de produção vigente no campo e perpetuado por suas elites. Para a CIA, as Ligas estavam amplamente doutrinadas pelo castrismo de Francisco Julião, Deputado Estadual de Recife e advogado dos camponeses do emblemático Engenho Galiléia, em Pernambuco, onde os latifundiários começavam a se sentir incomodados com os questionamentos dos trabalhadores em relação ao domínio exacerbado sofrido por eles.

Já no campo sócio-econômico (porém tendo em vista a influência ideológica), os EUA viam a pobreza do Nordeste como consequência de:

\footnotetext{
Fatores de alta importância para a propagação do problema comunista, sendo necessário o desenvolvimento de programas sociais, especialmente em regiões menos favorecidas pelas condições geográficas ou que ainda estejam em desenvolvimento. Atitudes tão simpáticas e humanitárias, que contribuiriam para o aprimoramento dos padrões de vida de regiões atrasadas, permitiriam indiretamente a abertura de novos mercados para um consumo mais amplo de produtos comerciais e engrandecer os lucros das organizações mais graúdas. ${ }^{X X I I}$
}

Portanto, os EUA conheciam a precariedade sócio-econômica da região Nordeste e compreendiam a necessidade de uma aproximação, principalmente por meio do desenvolvimento estrutural, que impedisse a politização das massas camponesas como em Cuba. A partir disso seriam pensados projetos experimentais que desembocariam na APP, evitando uma intervenção estadunidense mais incisiva e repreensível por parte da opinião internacional, pelo menos até 1964, ao mesmo tempo buscando meios de edificar entre os pobres os emblemas yankees da cooperação pelo desenvolvimento latino-americano. As comparações entre o Nordeste e Cuba neste período são enfáticas em outros documentos da CIA entre o fim dos anos 1950 até depois do golpe civil-militar.

Segundo um boletim da CIA de 1964, o problema resultante de demandas mais agudas nos países subdesenvolvido, sobretudo nos da América Latina, era o da reforma

Cadernos do Tempo Presente, São Cristóvão-SE, v. 09, n. 01, p. 64-81, jan./jun. 2018| http://www.seer.ufs.br/index.php/tempo 


\title{
GUERRA FRIA, TERRA SECA: O "PERIGOSO" NORDESTE BRASILEIRO SOB O OLHAR DA CIA E DA IMPRENSA ESTADUNIDENSE NO ALVORECER DOS ANOS 1960
}

\section{PEDRO CARVALHO OLIVEIRA}

agrária. As regiões rurais possuíam uma grande escassez de terras propícias para a lavoura, diz o texto. E o relator comenta sobre como nessas regiões os comunistas tiveram sucesso em impedir que os governos alcançassem progressos significativos para o avanço da democracia. Ao contrário dos EUA, quando sua população era majoritariamente rural, a geografia dos países latino-americanos trazia maiores dificuldades para o plantio de pequena escala, o que se tornou oneroso para os pequenos fazendeiros. É contraditoriamente nas áreas rurais, onde normalmente as pessoas teriam mais alimentos, que se encontravam os mais altos índices de subnutrição no Brasil.

O relatório comenta ainda a contradição que envolve o decréscimo do número de alimentos e o crescimento populacional em zonas rurais da América Latina, o que Josué de Castro XXIII explica comentando a necessidade de os sertanejos manterem contingentes visto que a mortalidade era altíssima. A fome nas zonas rurais latinoamericanas aparece como fator de energização da reforma agrária, pois os camponeses se veem famintos mesmo que próximos de famílias tão abastadas, para as quais trabalhavam. Apenas em alguns casos os governos conseguiram empreender soluções a esses problemas e em pouquíssims casos teriam se esforçado de forma suficiente para tanto, subestimando a capacidade dos pobres de tomarem consciência sobre as razões de sua condição. O relator afirma que uma das dificuldades para este esforço estava no fato de que a maioria dos latifundiários fechava os olhos para as pressões dos camponeses. Ao mesmo tempo, governos como o da Venezuela cediam minimamente a algumas exigências buscando evitar conflitos. $O$ Brasil tinha, então, um problema de terras proporcional ao seu tamanho; junto a Peru e México, possuía um grande número de comunistas dispostos a explorar as reivindicações dos camponeses em nome de ganhos políticos.

\begin{abstract}
No Brasil, a violência tem sido ligeiramente atribuída ao grande número de camponeses organizados e liderados por comunistas. As atividades mais espetaculares tem sido protagonizadas pelas Ligas Camponesas, em especial no Nordeste. Originalmente organizada em 1957, foram tomadas em 1959 por Francisco Julião, um advogado radical com ligações Castristas e a favor da revolução sangrenta como única forma de se obter transformações sociais. Julião fez viagens frequentes a Cuba, recebeu armas e dinheiro de Castro, queimou alguns canaviais, e por um tempo esteve em aberta revolta contra o governo. Em outubro de 1962 foi eleito Deputado Federal de Pernambuco, o que lhe deu imunidade parlamentar. Depois do golpe militar que derrubou o presidente João Goulart, Julião fugiu mas acabou sendo preso mesmo com sua imunidade ${ }^{\mathrm{XXIV}}$.
\end{abstract}

A União dos Trabalhadores Agrícolas do Brasil, nome oficial das chamadas Ligas Camponesas, teria sido alvo de interesse do Partido Comunista Brasileiro (PCB), ao menos da fração do partido que era pró-moscou (a que se tornaria o PCdoB), tendo decorrido disso um rompimento de relações entre Julião e esta ala do comunismo stalinista. De todo modo, o problema para o relator não eram as reformas agrárias necessitadas pelos camponeses em si, mas o controle ou os cacoetes comunistas presentes nas ações e lutas em nome delas capazes de comprometer a hegemonia das classes superiores. Ao final, o documento afirma que todas as reformas agrárias bem sucedidas, exemplificadas nele, ocorreram dessa forma pela ausência de qualquer participação ou agitação comunista. Quando os comunistas se envolveram ou se

Cadernos do Tempo Presente, São Cristóvão-SE, v. 09, n. 01, p. 64-81, jan./jun. 2018| http://www.seer.ufs.br/index.php/tempo 


\section{GUERRA FRIA, TERRA SECA: O "PERIGOSO" NORDESTE BRASILEIRO SOB O OLHAR DA CIA E DA IMPRENSA ESTADUNIDENSE NO ALVORECER DOS ANOS 1960}

\section{PEDRO CARVALHO OLIVEIRA}

preocuparam com os camponeses, segundo o relator, exploraram seus interesses em nome des seus próprios e exacerbaram os antagonismos. Ou seja, as reformas precisavam ser moderadas sob uma égide política liberal, onde as estruturas estabelecidas e as hierarquias sociais permanecessem as mesmas; qualquer coisa para além disso aparecia como algo extremamente negativo.

O golpe de 1964 foi dado às pressas e de forma precipitada. O presidente João Goulart acreditava que a vitória do presidencialismo no plebiscito de 1963 fora uma vitória política sua, pouco depois de ter divulgado o Plano Trienal de Celso Furtado. Esse plano contrariou profundamente as lideranças comunistas do $\mathrm{PCB}$, desvelando a dissonância entre o partido e o presidente, já acusado de flertar com o comunismo. A luta por reformas, mais tarde, possibilitou a mobilização de forças revolucionárias de forma aguda no Brasil naquele momento, preocupando as classes superiores $\mathrm{e}$ entusiasmando as subalternas. Diante disso, tanto o PCB quanto outras forças progressistas, a exemplo da Ação Popular, haviam conquistado bastante solidez e eram entusiastas das reformas de base que Jango abraçou pouco antes de ser deposto. Este abraço fora uma tentativa do presidente, tendo suas forças ainda tolhidas pelo parlamentarismo vigente, para manter o apoio das esquerdas ainda que buscasse respaldo entre setores mais conservadores. Havendo fracassado na busca por apoio no Congresso, voltou-se às reformas de base como último recurso para encontrar suporte entre as massas ${ }^{\mathrm{XXV}}$.

Esta aproximação de Jango com forças à esquerda ávidas pelas reformas causaram a ruína do então presidente, derrubado a primeiro de abril de 1964 pelas Forças Armadas apoiadas vigorosamente pelos Estados Unidos e pelas classes superiores brasileiras. Jango era visto pelos estadunidenses não como um comunista ideológico, mas como um oportunista ${ }^{\mathrm{XVI}}$. Dessa forma, era mister para os EUA que o presidente se convencesse de que a melhor solução para sanar os problemas brasileiros era se alinhar a seu projeto de desenvolvimento, a APP. Para Jango, sua viagem aos EUA frente a este explosivo contexto significaria um potencial arrefecimento do descontentamento de militares e forças políticas conservadoras em relação às desconfianças sobre ele, o que não aconteceu.

Em meio a este clima efervescente, os EUA estruturaram estratégias diversas a fim de ampliar barreiras a possíveis insurgências comunistas no Nordeste do Brasil ainda antes do golpe de 1964 ser efetivado. Phyllis Parker ${ }^{\text {XXVII }}$ comenta que Riordan Roett, em The Politics of Foreign Aid (A Política de Ajuda Externa), descreve como, no "Nordeste do Brasil, dinheiro americano era destinado a projetos que iriam beneficiar candidatos governamentais conservadores com a esperança de influenciar aquelas eleições em favor dos anticomunistas". Se alguma reforma existisse, e elas eram necessárias (os EUA sabiam disso), ela jamais poderia ser feita pela via esquerda.

Além desta constatação, permanece uma outra facilmente explicitada pelos documentos aqui analisados: o Nordeste do Brasil era, para a maior potencia interessada em barrar o comunismo no Ocidente e docilizar os trabalhadores pobres do campo, uma região perigosa e propensa à subversão. Não apenas os relatórios e boletins da CIA expõem isso, mas artigos e reportagens em tradicionais meios de comunicação

Cadernos do Tempo Presente, São Cristóvão-SE, v. 09, n. 01, p. 64-81, jan./jun. 2018| http://www.seer.ufs.br/index.php/tempo 


\section{GUERRA FRIA, TERRA SECA: O "PERIGOSO" NORDESTE BRASILEIRO SOB O OLHAR DA CIA E DA IMPRENSA ESTADUNIDENSE NO ALVORECER DOS ANOS 1960}

\section{PEDRO CARVALHO OLIVEIRA}

estadunidenses reforçam tal ideia. Além do já mencionado clássico artigo de Tad Szulc para o The New York Times, o correspondente e outros jornalistas do diário publicaram textos sobre os problemas enfrentados pelo Nordeste brasileiro e o perigo de levantes comunistas decorrentes deles. A tônica era frequentemente a mesma: os nordestinos são pobres demais para não aceitar qualquer doutrina idológica populista.

Em 1961, o canal televisivo estadunidense $\mathrm{ABC}$ deu aval à produção do documentário Brazil - The troubled land que, apesar de ter ido ao ar somente em 1964 (sua produção três anos antes convenientemente coincide com o momento no qual as atenções do poder de Estado dos EUA se voltaram ao Nordeste brasileiro, bem como com o ano no qual Jânio Quadros, em ousada atitude, porém explicável frente a importantes negociações feitas com o ministro da economia cubana, condecorou Che Guevara com a Ordem do Cruzeiro do Sul), remonta, de forma dramática, a penúria vivida pelo povo sertanejo em Pernambuco, além de acusar o já mencionado Francisco Julião de ser um demagogo a serviço de Cuba. Sua demagogia estaria a enfeitiçar os nordestinos, desprovidos de qualquer potencialidade de autonomia, no sentido do comunismo.

Helen Jean Rogers, diretora do documentário, tinha ligações com a Casa Branca e sua película, veiculada nos EUA pouco antes do golpe civil-militar que depôs João Goulart, tornou crescente o estígma do Nordeste do Brasil não apenas como região castigada pela pobreza derivada da exploração e da natureza, mas como região à qual o "mundo livre" deveria chegar antes dos soviéticos. Em sua visceral narrativa, a diretora descreve como essa corrida estava sendo perdida pelo bloco capitalista.

Francisco Julião, o suposto agitador castrista entre os camponeses e bastante exposto no documentário de Rogers, era bastante visado pela CIA no início dos anos 1960. Em boletim emitido em 1963 há um alerta sobre os jornais brasileiros publicados em 6 de março de 1963 não noticiarem, conforme combinado, a lista dos responsáveis pelo Congresso Continental de Solidariedade a Cuba, organizado, dentre outros membors do PCB, por Julião, de acordo com o que fora publicado no Washington Post a 11 de março daquele mesmo ano. Alertou também que o jornal Correio da Manhã, do Rio de Janeiro, informou que o Conselho de Segurança Nacional Brasileiro e o Serviço Secreto das Forças Armadas poussuíam quatro documentos secretos tirados de Luiz Carlos Prestes, também envolvido na organização do congresso, desde sua volta de Havana. A organização do congresso vinha sendo investigada desde que Francisco Julião, segundo mencionado pelo documento, leu em certa ocasião (não esclarecida pelo relator) um manifesto convocando os militantes a participarem. Tal fato teria sido noticiado no jornal comunista O Semanário, em setembro de 1962. O jornal Última Hora de março de 1963 comunicou nomes de pessoas públicas, entre políticos, intelectuais e artistas, que assinaram o manifesto pedindo o congresso. O mesmo seria noticiado no jornal cubano Revolucion, em março de 1963, quando Prestes deu uma entrevista listando os participantes do congresso ${ }^{\text {XXVIII }}$.

Ainda em 1959, a edição de 22 de junho do jornal O Globo ${ }^{\text {XXXX }}$ se dedicou a expor Francisco Julião como um agitador entre os camponeses de Pernambuco. Não há na matéria um alarde tão grande a respeito das condições nas quais viviam os sertanejos,

Cadernos do Tempo Presente, São Cristóvão-SE, v. 09, n. 01, p. 64-81, jan./jun. 2018| http://www.seer.ufs.br/index.php/tempo 


\section{GUERRA FRIA, TERRA SECA: O "PERIGOSO" NORDESTE BRASILEIRO SOB O OLHAR DA CIA E DA IMPRENSA ESTADUNIDENSE NO ALVORECER DOS ANOS 1960}

\section{PEDRO CARVALHO OLIVEIRA}

mas o deputado estadual é creditado erroneamente como fundador das Ligas Camponesas e íntimo dos líderes revolucionários cubanos. Crítico ao regime castrista, o jornal antecipava o The New York Times, mas não necessariamente o conhecimento de Washington sobre o caso. O frenesi estadunidense pode ter influenciado a imprensa brasileira, notadamente aquela desinteressada quanto às tendências de esquerda? Havemos de examinar isto oportunamente.

Por ora, eis alguns poucos exemplos, perto da vastidão documental existente sobre o assunto, correspondentes à visão dos EUA sobre o Nordeste brasileiro num delicado momento político para a América Latina. As autoridades estadunidenses, frente a um avanço do socialismo na região, tratou de examinar as características determinantes para tal ocorrência e buscou, por meio de sua diplomacia e de sua forte influência, sobretudo econômica, freá-la onde fosse possível. Não se trata de uma coincidência a forma como os textos elaborados pela inteligência estadunidense, de linguagem técnica e formal, tenham sido traduzidos por grandes meios de comunicação conjugados a contornos emocionantes e dramáticos.

\section{Hegemonia e consenso: o Nordeste seria mesmo uma nova Cuba?}

No sentido pelo qual estamos seguindo, dois conceitos de Antonio Gramsci são caros ao nosso breve exame. Primeiro, o conceito de hegemonia; depois, o de aparelhos privados de hegemonia. No primeiro caso, Gramsci ${ }^{\mathrm{XXX}}$ nos lembra que o poder de uma classe (superior, como a política) sobre outras (subalternas, como as populações civis) se estabelece em um equilíbrio entre a força, sob o uso de instrumentos de repressão, e o consenso, fabricado, dentre outras formas, por meio da imprensa. Para o autor, a cultura de uma sociedade é a cultura das classes hegemônicas. A hegemonia seria a rede de relações das classes superiores que permitiria aliar ao seu projeto parcelas consideráveis das demais classes, contendo consensualmente as possibilidades de eclosão de crises ao seu estabelecimento. A imprensa, gerida pelos grande conglomerados cujos interesses em defender a hegemonia existente estimula uma produção voltada a isso, grosso modo se empenha na manutenção e na preservação das classes superiores no poder uma vez que seus gestores são parte ou almejam ser parte de sua distribuição de poder. Assim, os meios de comunicação, também parte das elites, acabam servindo a propósitos específicos e incidem sobre uma produção cultural (simbólica) para gerar um consenso. Portanto, para convencer a sociedade sobre as necessidades de preservação do sistema hegemônico estabelecido, da dinâmica social conveniente aos "donos do poder".

O consenso hegemônico visa principalmente diluir-se por meio da cultura social, para que se estabeleça de forma sútil e pouco evidente. Conforme isto ocorre, não sem um esforço em conjunto das elites, a sociedade civil, sobretudo as classes subalternas, acabam por assimilar esta cultura e colaboram para a manutenção da mesma por estarem desprovidades de consciência sobre esse domínio, ao contrário dos seus dirigentes XXXI . Para que isso ocorra, torna-se necessário convencer as classes subalternas, por exemplo, de que, primeiro, o sistema político e econômico aos quais orbitam são naturalmente edificados e, depois, que elas mesmas são responsáveis por sua condição social e que qualquer pessoa pode alcançar o terreno das elites a partir de seu esforço próprio. A separação entre ambas as classes se estabelece, além de tudo, por

Cadernos do Tempo Presente, São Cristóvão-SE, v. 09, n. 01, p. 64-81, jan./jun. 2018| http://www.seer.ufs.br/index.php/tempo 


\section{GUERRA FRIA, TERRA SECA: O "PERIGOSO" NORDESTE BRASILEIRO SOB O OLHAR DA CIA E DA IMPRENSA ESTADUNIDENSE NO ALVORECER DOS ANOS 1960}

\section{PEDRO CARVALHO OLIVEIRA}

meio de uma cultura específica que, embora em determinados momentos se confunda com outra, é exclusiva a cada uma delas, sendo necessário, mais do que vencer as condições econômicas, compartilhar destes denominadores culturais comuns.

No segundo caso, o dos aparelhos privados de hegemonia, cuja noção a seu respeito nos faz penetrar mais profundamente na lógica do consenso, Gramsci ${ }^{\text {XXXII }}$ nos ajuda a explorar como elementos linguísticos, mais especificamente a linguagem documental dos aparelhos de Estado, encontram alguns empecilhos em suas possibilidades de transmissão para a sociedade. Os jornais, no entanto, forjam suas matérias de acordo com o arsenal simbólico (cultural) de um ou outro povo, bem como pela intencionalidade política de seu corpo editorial responsável por este processo. Obviamente, com o passar do tempo, estas criações são alteradas pelos processos alavancados por dinâmicas sociais, porém sua lógica esbarra nas noções de cada sociedade sobre uma ou outra definição cultural.

Os aparelhos privados de hegemonia seriam instituições midiáticas particulares que circulam suas ideias em nossas sociedades por meio da imprensa, longe de ser isenta e imparcial como costumeiramente se define, sem qualquer marca de seus idealizadores e patrocinadores, pertencentes a elites específicas interessadas em difundir sua cultura, de concretizar sua hegemonia. Estes aparelhos formam opinião, impulsionam o consenso e garantem, em parte, a estabilidade da hegemonia e de seus discursos, de sua cultura, de seu aparato simbólico. Com isso, a sociedade permanece ordenada ao seu agrado.

Nos voltando a um panorama menos amplo, podemos dizer que se 1) a hegemonia das classes superiores se estabelece, entre outras coisas, por meio da cultura; 2) esta cultura cria um consenso capaz de dar às classes superiores alguma legitimidade quanto à sua posição social; 3) este consenso se enraíza por meio de uma linguagem específica e 4) tal linguagem necessita ser adaptada para ser compreendida embora não por completo (visto que um conhecimento mais amplo sobre ela poderia levar a um questionamento mais incisivo pelas sociedades), é possível que documentos oficiais (institucionais) e a narrativa midiática, imbuídos de intenções semelhantes, funcionem respectivamente como matéria-prima e produtora do consenso.

Os documentos da CIA aqui averiguados seriam, segundo o que propomos, a constatação técnica do Estado, composto por e defensor de uma classe social específica, a respeito de um problema: a possibilidade de recorrência do socialismo na América Latina, visto que no Nordeste brasileiro, comparado a Cuba, existia um contexto análogo ao cubano e uma série de outras marcas do potencial local a ser explorado pelos soviéticos. Mas estes documentos encontram-se profundamente distantes da superfície social. No trajeto até ela, foram necessárias mudanças para viabilizar a compreensão da sociedade de forma conveniente aos produtores deste consenso quanto ao problema localizado pelo Estado, tutelado hegemonicamente.

Este suposto problema enfatizado pela inteligência estadunidense encontrou respaldo no Brasil. Conforme nos aponta Vandeck Santiago XXXIII, no início dos anos 1960 as Ligas Camponesas, existentes desde os anos 1940 sob a liderança do PCB mas ainda pouco expressivas, transformam-se em ameaça à paz agrária segundo, entre outras

Cadernos do Tempo Presente, São Cristóvão-SE, v. 09, n. 01, p. 64-81, jan./jun. 2018| http://www.seer.ufs.br/index.php/tempo 


\section{GUERRA FRIA, TERRA SECA: O "PERIGOSO" NORDESTE BRASILEIRO SOB O OLHAR DA CIA E DA IMPRENSA ESTADUNIDENSE NO ALVORECER DOS ANOS 1960}

\section{PEDRO CARVALHO OLIVEIRA}

coisas, a narrativa de grande parte da imprensa em sintonia com os latifundiários. Antonio Torres Montenegro ${ }^{\text {XXIV }}$ também destaca como neste período que compreende a transformação das "Ligas Camponesas em um amplo instrumento de organização e luta dos trabalhadores até o golpe militar tornou o Nordeste objeto de incontáveis reportagens na imprensa nacional". O autor destaca as reportagens feitas pelo jornalista Antonio Callado para o jornal carioca Correio da Manhã, publicadas em setembro de 1959, sobre a situação política do Nordeste frente às Ligas. Trata-se do mesmo jornal que em 11 de fevereiro de 1963 noticiaria a posse de importantes documentos confiscados de organizadores do Congresso Continental de Solidariedade a Cuba, sobre o qual comentamos anteriormente. O mesmo veículo que em 1964 publicou o talvez mais famoso editorial jornalístico a favor do golpe civil-militar que seria deflagrado em $1^{\circ}$ de abril, intitulado "Basta!", exigindo a deposição do presidente João Goulart.

Portanto, verificamos assim como a tradutibilidade existente na linguagem documental do aparelho de Estado estadunidense encontrou força para ecoar no Brasil especialmente após a Revolução cubana - retratado de forma mais acessível a fim de criar um consenso. Um consenso desejado também pelas classes superiores brasileiras na busca pela manutenção de seu poder, ameaçado por discursos progressistas questionadores de sua existência.

Isso ocorre porque "as elites latino-americanas aproveitam privilégios e ascensão política como resultado de sua colaboração na defesa dos interesses dos EUA"XXXV , visto que as classes superiores, com mais ou menos poder político global, fazem parte de um todo com pequenas variáveis, mas com os mesmos interesses. Portanto, para as classes superiores brasileiras a soberania nacional em termos políticos parece menos importante do que a preservação de seus privilégios. Por isso o consenso sobre o perigo representado pelo Nordeste até 1964 era uma ideia compartilhada pelas classes hegemônicas de Brasil e EUA.

Este consenso, o de que o Nordeste brasileiro representava um perigo por sua pobreza, não se desfaz de uma hora para outra. As marcas do estigma provocado por ele ressoam no tempo presente e nos fazem questionar sobre sua responsabilidade em torno da imagem do Nordeste e dos nordestinos predominante no país hoje, mesmo esta imagem não tendo sido criada nos anos 1960. Como naquele tempo, os nordestinos muitas vezes são representados pelo consenso como incapazes de votar responsavelmente, ou de desconfiar do socialismo: estariam aptos a acolher propostas assistencialistas ou ditas totalitárias que solucionassem os seus problemas estruturais sem discernir a respeito de quem as propõe.

\section{Considerações finais}

Em 2017, um ano depois de consumada a deposição da presidente Dilma Rousseff, a vereadora farroupilha Eleonora Broilo (PMDB), declarou em uma plenária da Câmara Municipal de Porto Alegre que:

Eu acho que os nordestinos sabem muito bem se unir, sim, para roubar. Eles sabem ganhar propina. Eu acho que eles sabem se unir para aumentar a corrupção. (...) Talvez até eles não saibam nem falar muito bem, mas sabem roubar que é uma maravilha ${ }^{\mathrm{XXVI}}$.

Cadernos do Tempo Presente, São Cristóvão-SE, v. 09, n. 01, p. 64-81, jan./jun. 2018| http://www.seer.ufs.br/index.php/tempo 


\section{GUERRA FRIA, TERRA SECA: O "PERIGOSO" NORDESTE BRASILEIRO SOB O OLHAR DA CIA E DA IMPRENSA ESTADUNIDENSE NO ALVORECER DOS ANOS 1960}

\section{PEDRO CARVALHO OLIVEIRA}

Após receber inúmeras críticas, a vereadora disse que sua declaração fora mal interpretada e descontextualizada. Tratava-se, segundo ela, de um embate a respeito de interesses políticos defendidos por alguns colegas e rejeitados por ela, que expressou sua indignação com a classe política do Nordeste, não com o povo nordestino. Sua incisiva decleração teria remetido ao ranço coronelista existente entre os políticos da região, perpetuando modelos políticos ultrapassados. Mesmo Broilo tendo se retratado, suas considerações reforçam um estigma antigo no qual está presente um preconceito triplo: um, sobre os nordestinos (a corrupção, a incompetência); outro, sobre o modo de os nordestinos fazerem política, como se destoante de todos os outros; um terceiro, sobre um fragmento do campo político do qual está distante, apelando assim para uma caracterização histórica preconceituosa.

De que forma se difere, por exemplo, a declaração da peemedebista dos ataques aos nordestinos feitos nas redes sociais por opositores de Dilma e do PT como os exemplificados no início deste artigo? Ambos são baseados em um conhecimento curto sobre uma realidade sócio-econômica e política da qual não fazem parte. Ambos associam os nordestinos, sejam eles políticos profissionais ou não, à corrupção e à conivência a modelos políticos a serem superados não por serem eleitores, mas por serem nordestinos. Ambos discutem política e sociedade sem levar em conta os processos históricos que levariam políticos e eleitores nordestinos a um comportamento distinto do que desejam.

Deixando de lado o comportamento dos políticos profissionais nordestinos, nos voltemos aos eleitores. Estes foram execrados por suposta conivência com a reeleição de um governo que, segundo a narrativa midiática, era corrupto e praticante de políticas assistencialistas; um governo da esmola, do "voto de cabresto" aceito por seus ditos dependentes. A própria mídia, em muito, fortaleceu estes discursos já presentes em nossa sociedade. No entanto, esta mesma imprensa alertou, no passado, a respeito da necessidade de se assistir o Nordeste para barrar a penetração comunista. Assim, podemos questionar: o problema é o assistencialismo ao Nordeste ou os agentes políticos encarregados de assistí-lo? Nos anos 1960, os nordestinos eram vistos como incapazes de vencer sua situação precária sem a ajuda do Estado, algo que, bem ou mal, foi constatado e assimilado pelos governos de democracia burguesa; por que nos anos 2010, parte da sociedade rechaça essa necessidade? Ora, nos anos 1960 os EUA, partícipe instrumental do golpe de 1964, não apenas alertou sobre a assistência ao Nordeste como algo imprescindível, mas também agiu para concretizá-la, acompanhada pelo Estado brasileiro e pela população receosa quanto ao comunismo. O que teria mudado?

Embora este trabalho suscite mais questionamentos do que buscas mais complexas para respondê-los, uma coisa podemos afirmar: vimos em 1964 um discurso de ódio à existência mínima de intenções progressistas, norteadas pela diminuição das disparidades de classe, fossem elas meras manobras institucionais ou não. Desde 2014, com a reeleição de Dilma, testemunhamos o crescimento vertiginoso de um ódio às classes que dependem do Estado não devido a uma letargia crônica derivada de sua genética, mas dos problemas causados por estas mesmas instituições.

Cadernos do Tempo Presente, São Cristóvão-SE, v. 09, n. 01, p. 64-81, jan./jun. 2018| http://www.seer.ufs.br/index.php/tempo 


\section{GUERRA FRIA, TERRA SECA: O "PERIGOSO" NORDESTE BRASILEIRO SOB O OLHAR DA CIA E DA IMPRENSA ESTADUNIDENSE NO ALVORECER DOS ANOS 1960}

\section{PEDRO CARVALHO OLIVEIRA}

Com o golpe parlamentar deflagrado contra Dilma em 2016, o ódio ao chamado neodesenvolvimentismo, com o qual famílias pobres do Nordeste saíram ganhando, atingiu profundamente os nordestinos, sobretudo os migrantes submetidos a subempregos, a trabalhos domésticos, entre outros, cujos direitos passaram a ser, mesmo que minimamente em comparação ao ideal, atendidos. No caso do Nordeste, a pobreza histórica ensina sobre a popularidade recente de um partido cujos benefícios prestados tiraram expressivamente milhares de pessoas da miséria. A necessidade de criticar este povo por tentar garantir a continuidade destes benefícios remete a uma cultura na qual qualquer revisão dessa história é travestida de ameaça. Assim, constatamos o discurso hegemônico que guia nossa sociedade e como ele tem funcionado: como gestor de uma execração generalizada aos pobres que respinga sobre os nordestinos, vistos como pobres de forma determinante.

\section{Notas}

\footnotetext{
I Doutorando pelo Programa de Pós-Graduação em História da Universidade Estadual de Maringá. Este texto foi produzido com financiamento CAPES.

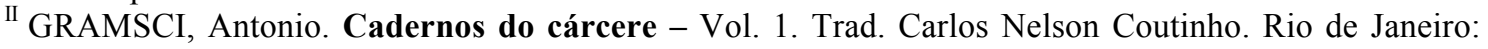
Civilização Brasileira, 1999.

III SARAIVA, José Flávio Sombra Saraiva. História das relações internacionais contemporâneas. São Paulo: Editora Saraiva, 2010, p. 02.
}

IV Ver "Culpa do Nordeste" - Disponível em <https://twitter.com/culpadonordeste>. Acesso em $12 / 12 / 2017$, às $14 \mathrm{~h} 00$.

V G1. "Jovem é condenada por mensagem contra nordestinos no Twitter" G1 SP, 2012. Disponível em < http://g1.globo.com/sao-paulo/noticia/2012/05/condenada-estudante-que-publicou-mensagem-contranordestinos-em-sp.html>. Acesso em 12/12/2017, às $14 \mathrm{~h} 05$.

VI ALBUQUERQUE JR., D. M. de. A invenção do Nordeste e outras artes. Rio de Janeiro: Editora Cortez, 1999, p. 56.

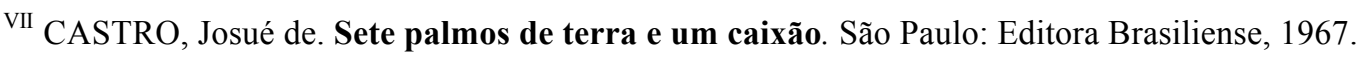

VIII Op. cit.

IX Op. cit.

X CASTRO, Iná Elias. O mito da necessidade: discurso e prática do regionalismo nordestino. Rio de Janeiro: Bertrand, 1992.

XI BURSZTYN, Marcel. O poder dos donos: planejamento e clientelismo no Nordeste. 1 ed. Petrópolis: Vozes, 1984.

XII Op. cit.

XIII Op. cit.

XIV Op. cit.

${ }^{\mathrm{XV}}$ CASTRO, Josué de. Op. cit., p. 150.

${ }^{X V I}$ CENTRAL Intelligence Agency. "Soviet bloc interests in Brazil's Northeast". Central Intelligence Agency. Memorando de 20 de agosto de 1961.

XVII CENTRAL Intelligence Agency. "Soviet bloc interests in Brazil's Northeast". Central Intelligence Agency. Memorando de 20 de agosto de 1961, p. 02, § 01.

XVIII DANTAS, San Tiago. Política Externa Independente. Brasília: Fundação Alexandre de Gusmão, 2011 .

XIX VISENTINI, Paulo F. O populismo e as relações Brasil-EUA (1945 a 1964): a dialética do alinhamento e da autonomia. In: MUNHOZ, Sidnei J.; TEIXEIRA DA SILVA, Francisco C. (Orgs.) Relações Brasil-Estados Unidos: os séculos XX e XXI. Maringá: EDUEM, 2011, p. 226.

Cadernos do Tempo Presente, São Cristóvão-SE, v. 09, n. 01, p. 64-81, jan./jun. 2018| http://www.seer.ufs.br/index.php/tempo 


\title{
GUERRA FRIA, TERRA SECA: O "PERIGOSO" NORDESTE BRASILEIRO SOB O OLHAR DA CIA E DA IMPRENSA ESTADUNIDENSE NO ALVORECER DOS ANOS 1960
}

\author{
PEDRO CARVALHO OLIVEIRA
}

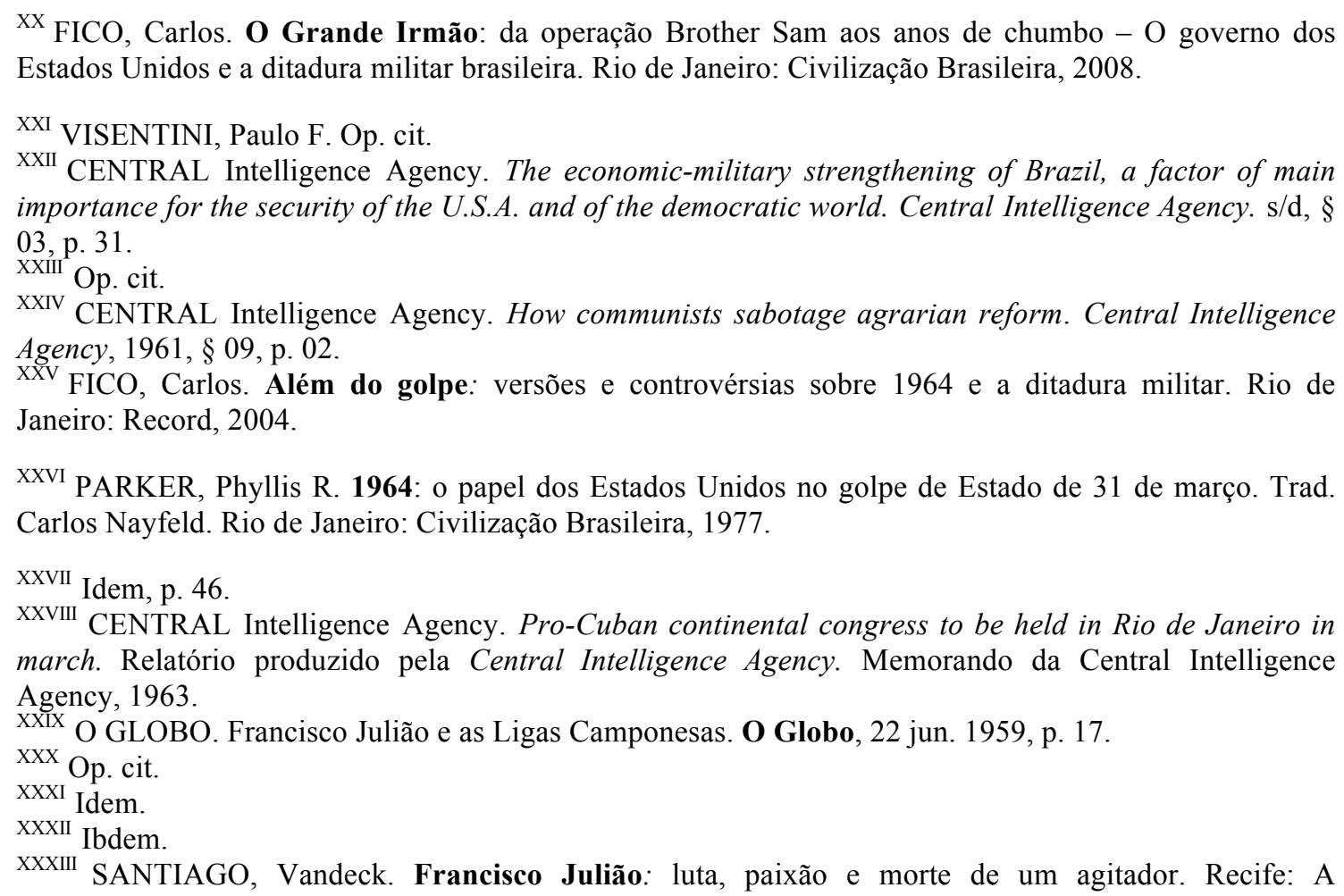
Assembléia, 2001.

Xxxiv MONTENEGRO, A. T. As Ligas Camponeas e os conflitos no campo. Saeculum: Revista de História, vol. 1, n. 18, João Pessoa, jan./jun. 2018, p. 17.

XXXV PÉREZ JR., Louis A. Dependency. In: HOGAN, Michael J.; PATERSON, Thomas G (Orgs.). Explaining the history of American foreign relations. New York: Cambridge University Press, 1991, p. 103.

XXXVI G1-RS. "Vereadora de Farroupilha diz que nordestinos "sabem roubar que é uma maravilha; vídeo". G1, 23 mai. 2017. Disponível em < https://g1.globo.com/rs/rio-grande-do-sul/noticia/vereadora-defarroupilha-diz-que-nordestinos-sabem-roubar-que-e-uma-maravilha-video.ghtml>. Acesso em 29/01/2018.

\section{Referências bibliográficas}

ALBUQUERQUE JR., D. M. de. A invenção do Nordeste e outras artes. Rio de Janeiro: Editora Cortez, 1999.

CASTRO, Josué de. Sete palmos de terra e um caixão. São Paulo: Editora Brasiliense, 1967.

DANTAS, San Tiago. Política Externa Independente. Brasília: Fundação Alexandre de Gusmão, 2011.

FICO, Carlos. Além do golpe: versões e controvérsias sobre 1964 e a ditadura militar. Rio de Janeiro: Record, 2004.

FICO, Carlos. O Grande Irmão: da operação Brother Sam aos anos de chumbo - O governo dos Estados Unidos e a ditadura militar brasileira. Rio de Janeiro: Civilização Brasileira, 2008.

Cadernos do Tempo Presente, São Cristóvão-SE, v. 09, n. 01, p. 64-81, jan./jun. 2018| http://www.seer.ufs.br/index.php/tempo 
GRAMSCI, Antonio. Cadernos do cárcere - Vol. 1. Trad. Carlos Nelson Coutinho. Rio de Janeiro: Civilização Brasileira, 1999.

MONTENEGRO, A. T. As Ligas Camponeas e os conflitos no campo. Saeculum: Revista de História, vol. 1, n. 18, João Pessoa, jan./jun. 2018, p. 11-21.

PARKER, Phyllis R. 1964: o papel dos Estados Unidos no golpe de Estado de 31 de março. Trad. Carlos Nayfeld. Rio de Janeiro: Civilização Brasileira, 1977.

PÉREZ JR., Louis A. Dependency. In: HOGAN, Michael J.; PATERSON, Thomas G (Orgs.). Explaining the history of American foreign relations. New York: Cambridge University Press, 1991, p. 99-110.

SANTIAGO, Vandeck. Francisco Julião: luta, paixão e morte de um agitador. Recife: A Assembléia, 2001.

SARAIVA, José Flávio Sombra Saraiva. História das relações internacionais contemporâneas. São Paulo: Editora Saraiva, 2010.

VISENTINI, Paulo F. O populismo e as relações Brasil-EUA (1945 a 1964): a dialética do alinhamento e da autonomia. In: MUNHOZ, Sidnei J.; TEIXEIRA DA SILVA, Francisco C. (Orgs.) Relações Brasil-Estados Unidos: os séculos XX e XXI. Maringá: EDUEM, 2011, p. 211-244.

Cadernos do Tempo Presente, São Cristóvão-SE, v. 09, n. 01, p. 64-81, jan./jun. 2018| http://www.seer.ufs.br/index.php/tempo 